\title{
Correction to: Research Misconduct in the Fields of Ethics and Philosophy: Researchers' Perceptions in Spain
}

\author{
Ramón A. Feenstra ${ }^{1}$ (1) Emilio Delgado López-Cózar ${ }^{2}$ (I) \\ Daniel Pallarés-Domínguez ${ }^{1}$ (i)
}

Accepted: 3 May 2021 / Published online: 20 May 2021

(c) Springer Nature B.V. 2021

\section{Correction to: Science and Engineering Ethics https://doi.org/10.1007/s11948-021-00278-w}

In the original article published online 25 January 2021 a mismatch between the figure legends and the figures has occurred. The correct versions of Figs. 1, 2 and 3 are given below.

The original article can be found online at https://doi.org/10.1007/s11948-021-00278-w.

\author{
Ramón A. Feenstra \\ feenstra@uji.es \\ Emilio Delgado López-Cózar \\ edelgado@ugr.es \\ Daniel Pallarés-Domínguez \\ dpallare@uji.es
}

1 Department of Philosophy and Sociology, Facultad de Ciencias Humanas y Sociales, Universitat Jaume I de Castellón, Avd/Sos Baynat s/n, 12071 Castellón de la plana, Spain

2 Department of Information and Communication, Facultad de Comunicación y Documentación, Universidad de Granada, Calle Campus De Cartuja, s/n, 18011 Granada, Spain 


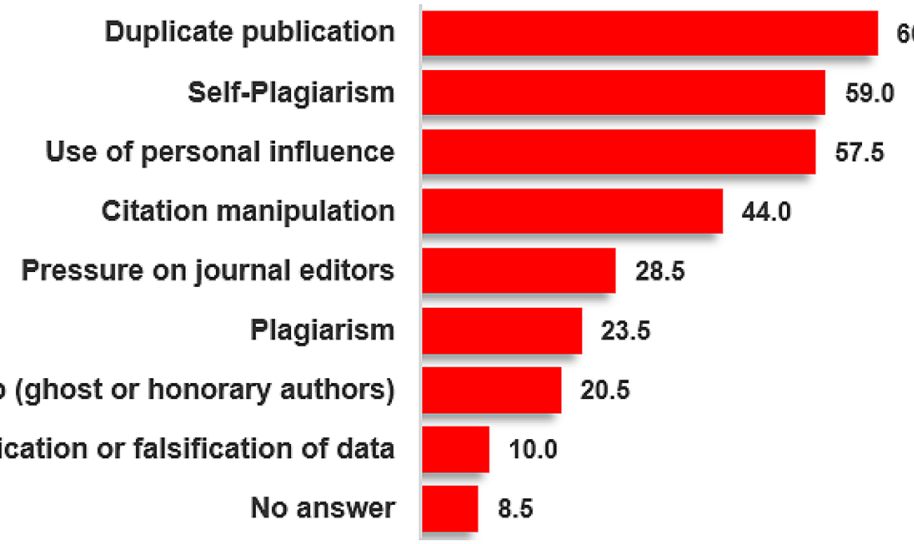

False autorship (ghost or honorary authors)

Fabrication or falsification of data

No answer

Fig. 1 Perception of research misconduct in publishing among Spanish university faculty and researchers in the fields of philosophy and ethics

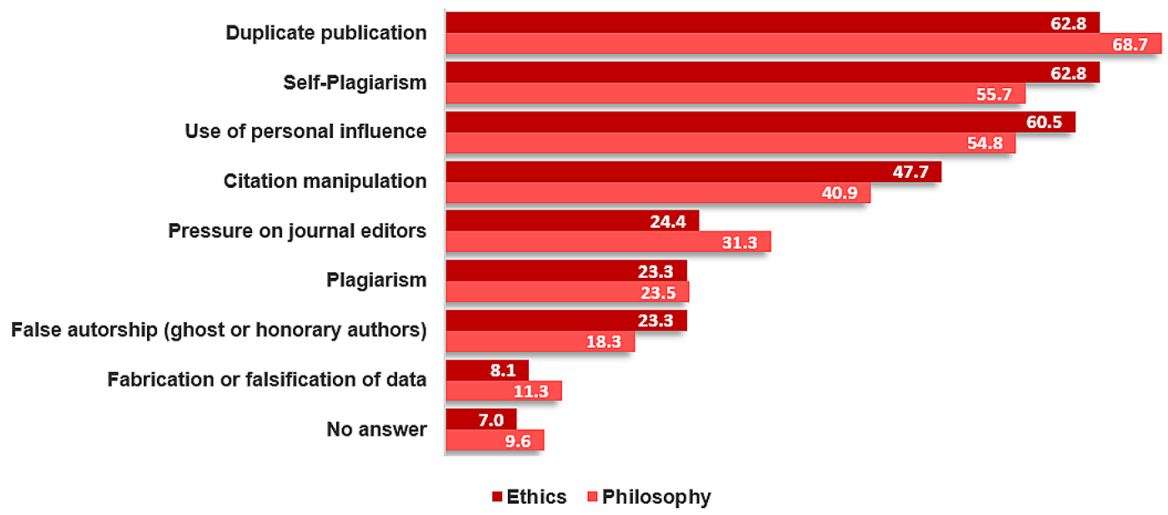

Fig. 2 Perception of research misconduct in publishing among Spanish university faculty and researchers in the fields of philosophy and ethics according to discipline 


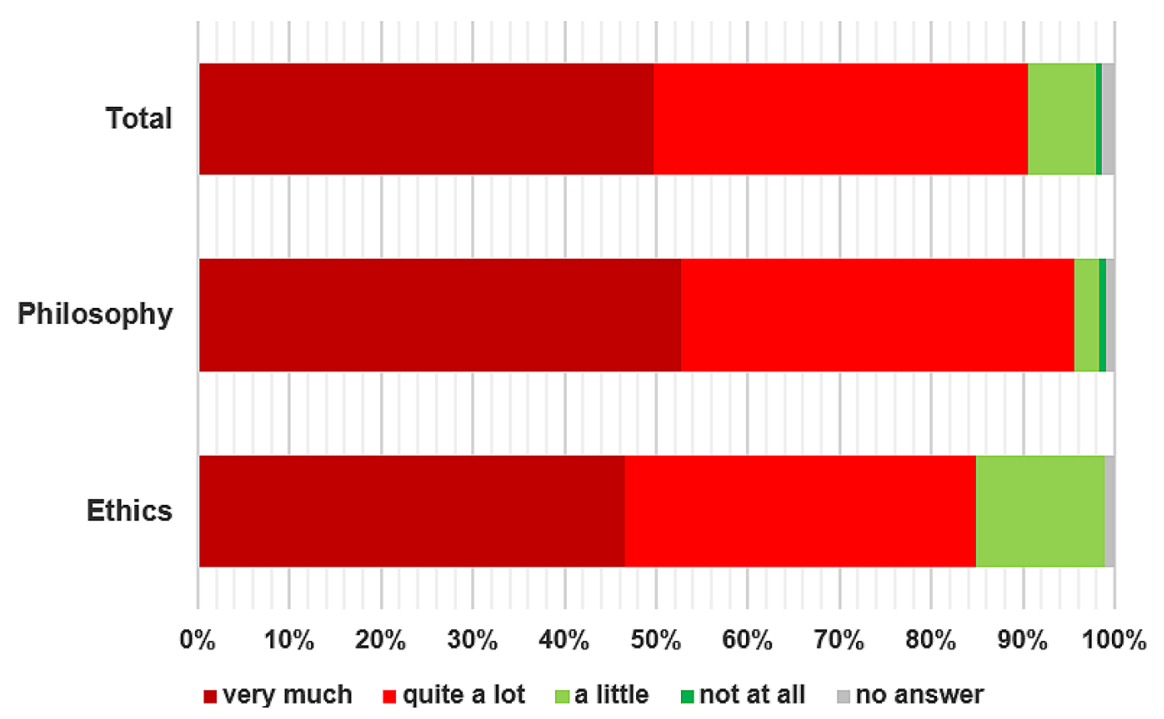

Fig. 3 Spanish philosophy and ethics researchers' opinions on the effect of the evaluation and promotion systems on their ethical behaviour according to discipline

Publisher's Note Springer Nature remains neutral with regard to jurisdictional claims in published maps and institutional affiliations. 